\title{
Deletion of Smad3 improves cardiac allograft rejection in mice
}

\author{
Ying-ying Wang ${ }^{1,2, *}$, Hong Jiang ${ }^{1, *}$, Yu-cheng Wang ${ }^{1,2}, X_{1 a 0-r u ~ H u a n g}{ }^{2,3}$, Jun Pan ${ }^{2,4}$, \\ Chen Yang ${ }^{2}$, Zhang-fei Shou ${ }^{1}$, Shi-long Xiang ${ }^{1}$, Da-jin Chen ${ }^{1}$, Hui-yao Lan ${ }^{2,3}$ and \\ Jiang-hua Chen ${ }^{1}$ \\ ${ }^{1}$ Kidney Disease Center, The First Affiliated Hospital, School of Medicine, Zhejiang University, Hangzhou, China \\ ${ }^{2}$ Li Ka Shing Institute of Health Sciences, and Department of Medicine and Therapeutics, The Chinese University of Hong \\ Kong, Hong Kong, China \\ ${ }^{3}$ Shenzhen Research Institute, The Chinese University of Hong Kong, Shenzhen, China \\ ${ }^{4}$ Key Laboratory of Combined Multi-organ Transplantation, Ministry of Public Health, State Key Laboratory for Diagnosis and \\ Treatment of Infectious Diseases, Division of Hepatobiliary and Pancreatic Surgery, The First Affiliated Hospital, School of \\ Medicine, Zhejiang University, Hangzhou, China \\ * These authors contributed to this work equally \\ Correspondence to: Jiang-hua CHEN, email: chenjianghua@zju.edu.cn
}

Hui-Yao LAN, email: hylan@cuhk.edu.hk

Keywords: Smad3, cardiac allograft rejection, Th 1, Th2, Th 17, Pathology

Received: May 05, 2015

Accepted: June 23, 2015

Published: July 13, 2015

This is an open-access article distributed under the terms of the Creative Commons Attribution License, which permits unrestricted use, distribution, and reproduction in any medium, provided the original author and source are credited.

\section{ABSTRACT}

T cells play a critical role in acute allograft rejection. TGF- $\beta /$ Smad 3 signaling is a key pathway in regulating $T$ cell development. We report here that Smad3 is a key transcriptional factor of TGF- $\beta$ signaling that differentially regulates $T$ cell immune responses in a mouse model of cardiac allograft rejection in which donor hearts from BALB/c mice were transplanted into Smad3 knockout (KO) and wild type (WT) mice. Results showed that the cardiac allograft survival was prolonged in Smad3 KO recipients. This allograft protection was associated with a significant inhibition of proinflammatory cytokines (IL-1 $\beta$, TNF- $a$, and MCP-1) and infiltration of neutrophils, $\mathrm{CD}^{+} \mathrm{T}$ cells, and $\mathrm{F4} / \mathbf{8 0}^{+}$macrophages. Importantly, deletion of Smad3 markedly suppressed T-bet and IFN-Y while enhancing GATA3 and IL-4 expression, resulting in a shift from the Th1 to Th2 immune responses. Furthermore, mice lacking Smad3 were also protected from the Th17-mediated cardiac injury, although the regulatory $T$ cell (Treg) response was also suppressed. In conclusion, Smad3 is an immune regulator in $\mathrm{T}$ cell-mediated cardiac allograft rejection. Loss of Smad3 results in a shift from Th1 to Th 2 but suppressing Th17 immune responses. Thus, modulation of TGF- $\beta / \mathrm{Smad} 3$ signaling may be a novel therapy for acute allograft rejection.

\section{INTRODUCTION}

Organ transplantation is the final definitive treatment for the end stage of many organ diseases. However, allograft rejection remains the main impediment in organ transplantation clinically. As immune regulatory cells, $\mathrm{CD}^{+} \mathrm{T}$ helper (Th) cells play a critical role in transplant rejection, especially in acute allograft rejection [1]. This is supported by the finding that adoptive transfer of $\mathrm{CD} 4^{+}$ $\mathrm{T}$ cells promotes but depletion of this $\mathrm{T}$ cell population inhibits allograft rejection $[2,3]$. It is now clear that naive $\mathrm{CD} 4^{+} \mathrm{T}$ cells can proliferate and differentiate into
Th cells including Th1, Th2, T regulatory (Treg) cells, and interleukin 17 (IL-17)-producing Th cells (Th17). Recent studies indicated that transforming growth factor- $\beta$ (TGF- $\beta$ ) is a master regulator in T cell development, homeostasis, tolerance, and differentiation during the immune response [4]. In mammals, 3 members of the TGF- $\beta$ family (TGF- $\beta 1$, TGF- $\beta 2$, and TGF- $\beta 3$ ) have been identified, with TGF- $\beta 1$ being the predominant form expressed in the immune system [5]. Binding of TGF- $\beta 1$ to its receptor II (T $\beta$ RII) can activate the TGF- $\beta$ receptor type I (T $\beta R I)-k i n a s e$, resulting in the phosphorylation of Smad2 and Smad3, two receptor-associated Smads. 
Subsequently, phosphorylated Smad 2 and Smad3 bind to the Smad4 and form the Smad complex, which translocates into the nucleus to exhibit its diverse biological activities under disease conditions [6]. Among Smad signals, Smad3 is a key regulator in $\mathrm{CD}^{+} \mathrm{T}$ cell differentiation as deletion of Smad3 impairs T cell immunity [7]. However, the function of Smad3 in regulating immune response during organ transplantation rejection remains largely unknown. In the present study, we tested the hypothesis that Smad3 may be a key regulator of TGF- $\beta$ signaling in cardiac transplantation rejection. The hypothesis was examined in an acute cardiac allograft rejection induced in $\mathrm{Smad} 3 \mathrm{KO}$ mice and the regulatory mechanisms of Smad3 in acute cardiac rejection were investigated.

\section{RESULTS}

\section{Loss of Smad3 inhibits cardiac inflammation and promotes cardiac allograft survival}

To investigate the role of Smad3 in acute allograft rejection, we transplanted the heart from BALB/c $\left(\mathrm{H}-2^{\mathrm{d}}\right)$ mice into Smad3 KO or Smad3 WT (B6 background, $\mathrm{H}-2^{\mathrm{b}}$ ) mice, or control BALB/c mice. When recipients were BALB/c mice, the cardiac grafts survived for more than 30 days without detectable cardiac inflammation. However, histology and immunohistochemistry detected that cardiac allografts in Smad3 WT mice developed a severe acute rejection with many $\mathrm{F} 4 / 80^{+}$macrophages and neutrophils infiltration and a marked upregulation of

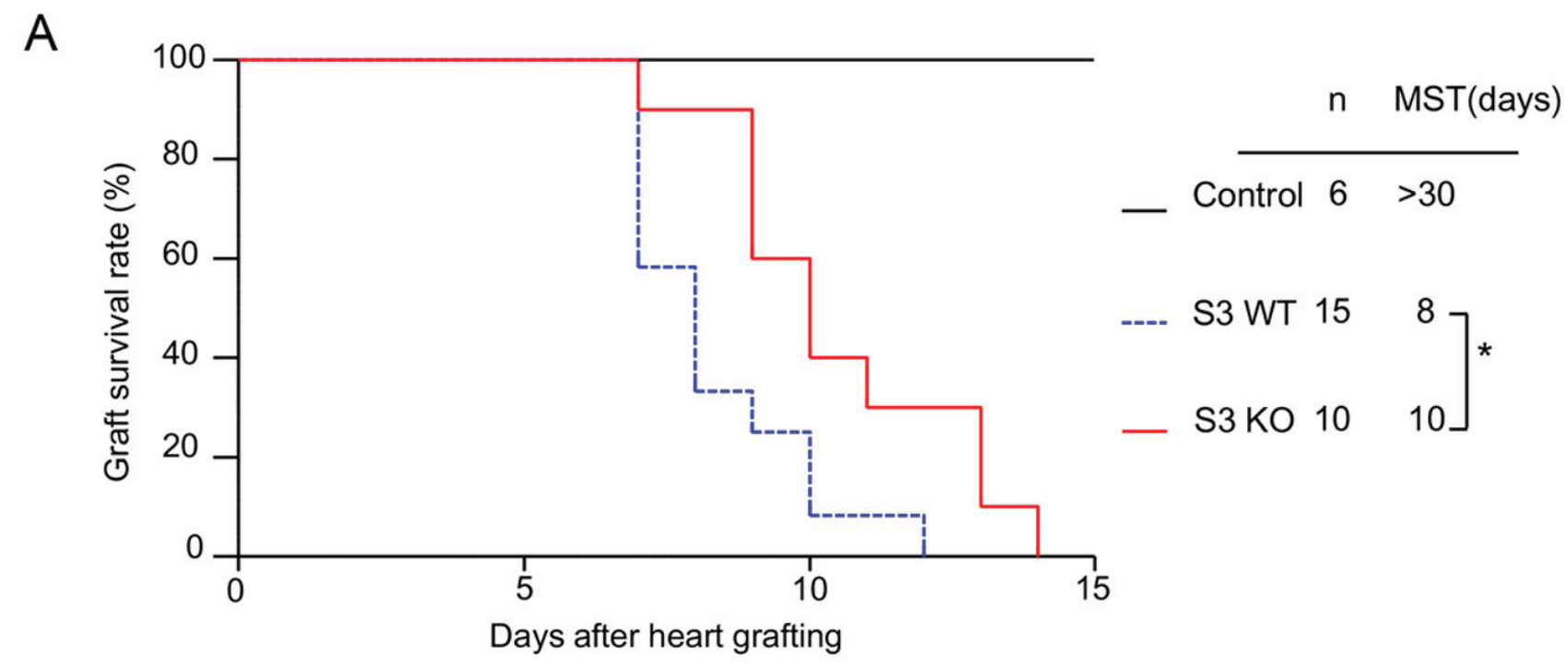

B

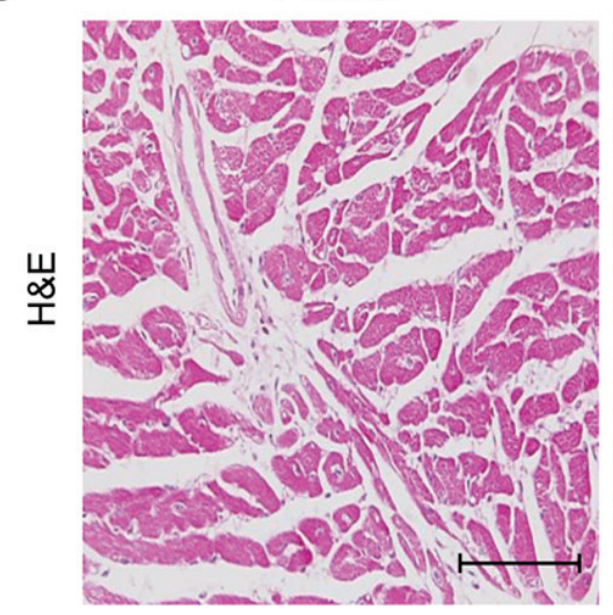

S3 WT

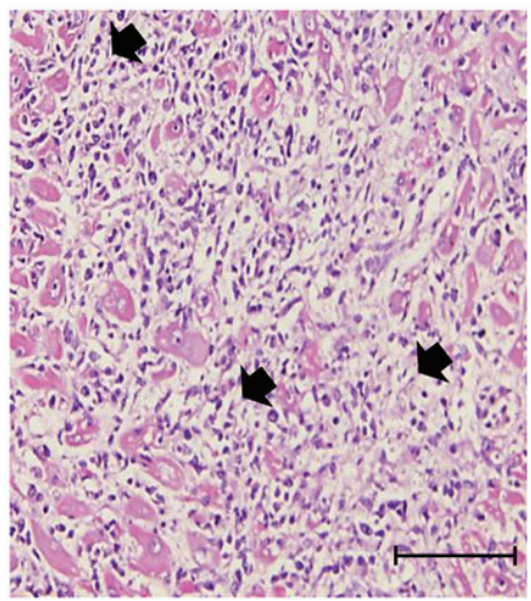

S3 KO

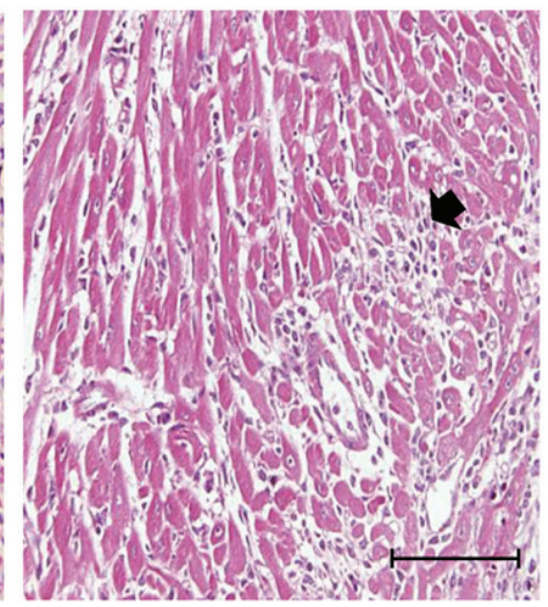

Figure 1: Deletion of Smad3 from the recipients significantly improves cardiac allograft rejection. A. Cardiac allograft survival rate. B. Histologic changes (H\&E staining) in cardiac allografts on postoperative days (POD) 7, black arrows show the loci of myocyte damage. Results show that deletion of Smad3 from the recipients results in prolonged allograft survival and less histological damage. ${ }^{*} p<0.05$ versus Smad3 WT mice; MST, median survival time; Scale bar $=100 \mu \mathrm{m}$. 
proinflammatory cytokines including IL- $1 \beta$, TNF- $\alpha$, and MCP-1, resulting in the lower graft survival rate (Figures 1-3). In contrast, cardiac allografts in Smad3 $\mathrm{KO}$ mice showed a less severe allograft rejection with moderate macrophages infiltration, a few neutrophils, and inhibition of IL-1 $\beta$, TNF- $\alpha$, and MCP-1 expression, resulting in an improvement of allograft survival (Figures 1-3). Interestingly, mice lacking Smad3 did not alter CD11 ${ }^{+}$ dendritic cells and $\mathrm{CD}^{+} \mathrm{T}$ cells infiltrating the graft when compared to the littermate Smad3 WT mice (Figure 2A, $2 \mathrm{D}, 2 \mathrm{E}$ and $2 \mathrm{H})$.
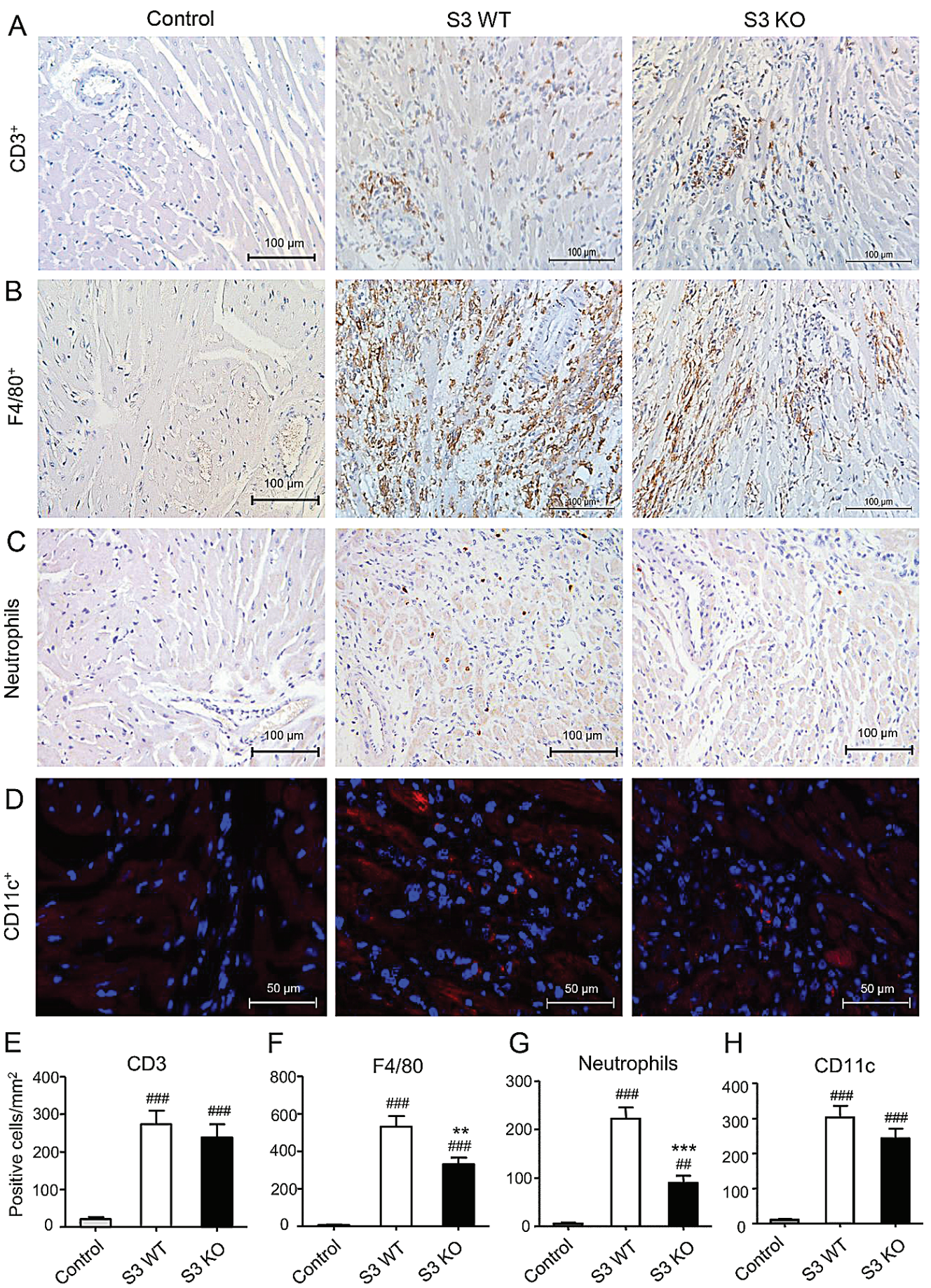

Figure 2: Deletion of Smad3 inhibits infiltration of inflammatory cells in cardiac allograft rejection. A. Immunohistochemistry shows $\mathrm{CD}^{+}$T cells, B. F4/80 macrophages, C. neutrophils, and D. CD11 c dendritic cells infiltration in cardiac allografts on POD 7. (E-H) Quantitative data of $\mathrm{CD}^{+}$cells, $\mathrm{F} 4 / 80^{+}$cells, neutrophils and CD11 $\mathrm{c}^{+}$cells infiltrating the allograft tissues. Data represent mean $\pm \mathrm{SEM}$ for

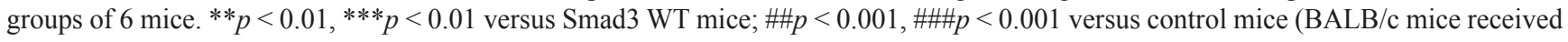
cardiac allografts from BALB/c mice). 
A
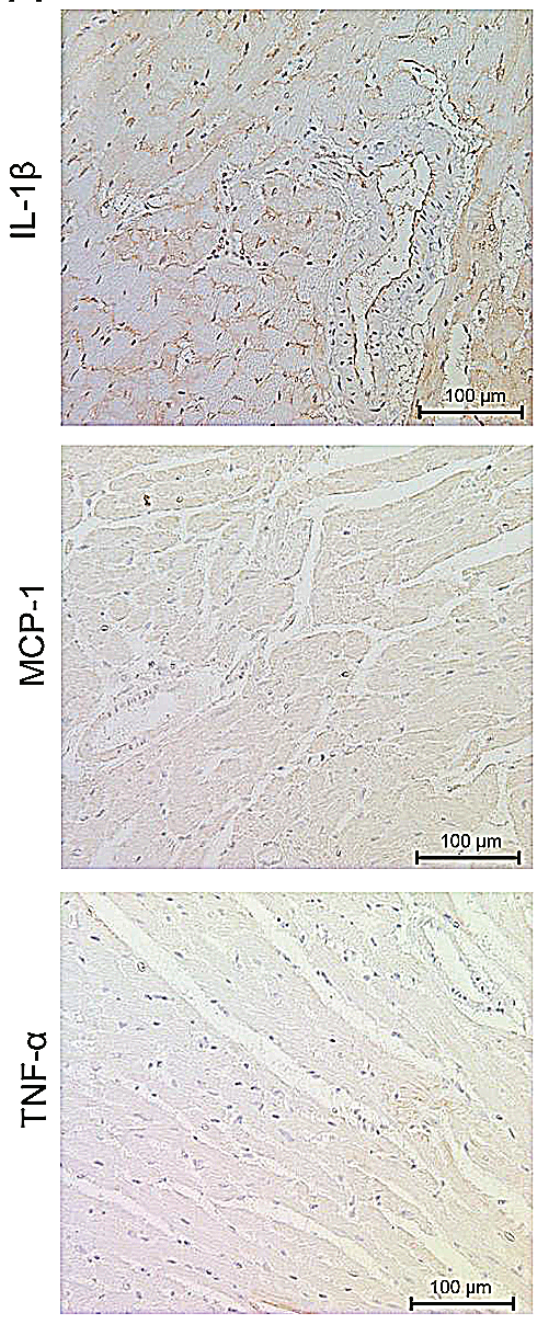

B

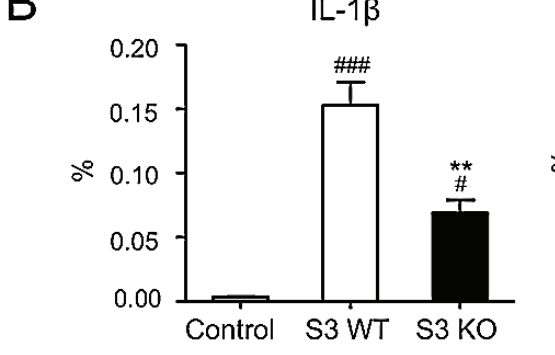

C

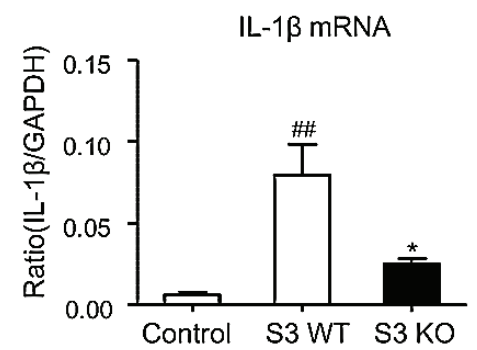

S3 WT
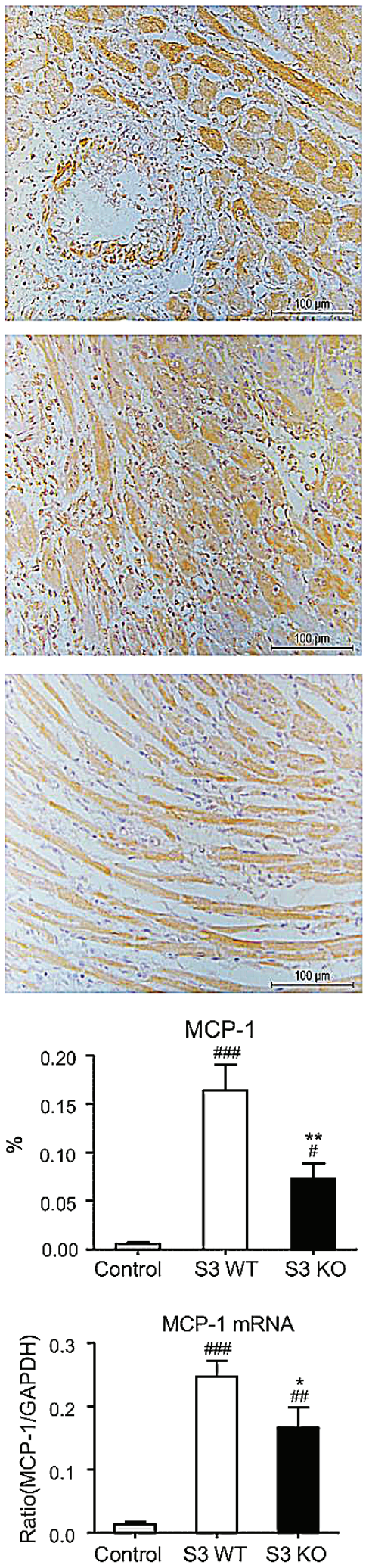

S3 KO
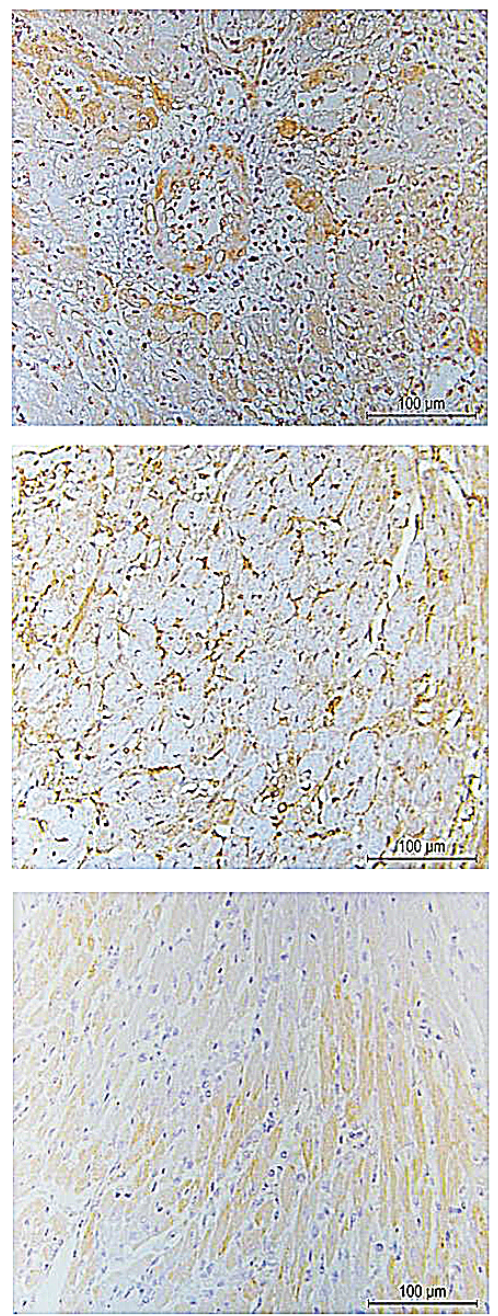

TNF- $\alpha$
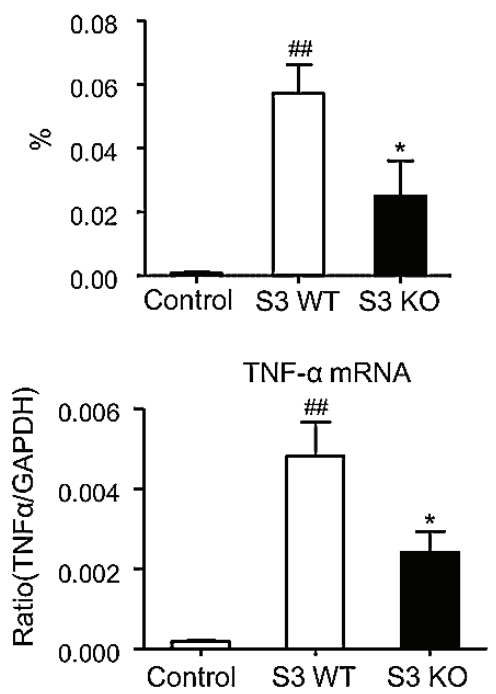

Figure 3: Improvement of cardiac allograft rejection in Smad3 deficient recipients is associated with inhibition of upregulation of proinflammatory cytokines. A. Expression levels of IL-1 $\beta$, MCP-1 and TNF- $\alpha$ in cardiac allografts on POD 7 by immunohistochemistry. B. Quantitative data of IL-1 $\beta$, MCP-1 and TNF- $\alpha$ from immunohistochemically stained tissues. C. Real-time PCR for IL-1 $\beta$, MCP-1 and TNF- $\alpha$ mRNA expression in cardiac allografts on POD 7. Data are expressed as the mean \pm SEM. ${ }^{*} p<0.05,{ }^{* *} p<$ 0.01 versus Smad3 WT mice; $\# p<0.05$, \#\#p <0.01, \#\#p<0.001 versus control mice. 


\section{Deletion of Smad3 results in a shift from Th1 to Th2 immune response in the donor heart with acute cardiac allograft rejection}

We next investigated the immunological mechanisms whereby deletion of Smad3 from the recipients improves cardiac allograft survival. We first examined the Th1 versus Th2 immune response in the grafted donor heart in Smad3 KO or WT mice. Two-color immunofluorescence and flow cytometry analysis found that although the number of $\mathrm{CD} 4^{+} \mathrm{T}$ cells infiltrating the cardiac graft were not significantly different between Smad3 KO and WT mice, mice lacking Smad3 showed a great suppression of the Th1 immunity in the grafted donor heart as demonstrated by a $40 \%$ reduction in the number of $\mathrm{CD}^{+} \mathrm{IFN}-\gamma^{+}$cells (Figure $4 \mathrm{~A}-4 \mathrm{C}$ ). In contrast, Th2 immune response was largely promoted in the grafted donor heart in Smad3 KO mice as evidenced by a $50 \%$ increase in the number of $\mathrm{CD} 4^{+} \mathrm{IL}-4^{+}$cells (Figure 4D-4F). Further studies by real-time PCR and western blot analysis also detected a marked suppression of the Th1 master transcriptional factor T-bet and its signature cytokine IFN- $\gamma$ in the grafted heart of Smad3 KO mice (Figure 5A and 5B), which was associated with a large increase in the Th2 immune response by doubling levels of GATA3 and IL-4 (Figure 5A and 5B). These results suggested that deletion of Smad3 results in a shift of the graft immunity from the Th1 to Th2 during acute allograft rejection. This was further supported by the finding that mice lacking Smad3 promoted Th2-dependent humoral immune response with higher levels of $\mathrm{IgG}, \mathrm{IgG} 1$, but lower levels of IgG2a deposition within the donor heart (Figure 5C). ELISA supported this notion that mice null for Smad3 developed higher levels of serum IgG and IgG1 but lower level of IgG2a when compared to Smad3 WT (Figure 5D).

To address whether the alternation of Th1 and Th2 immune responses within the cardiac allografts of Smasd3 $\mathrm{KO}$ recipients is associated with $\mathrm{T}$ cell differentiation systemically, we detected the associated cytokines in serum by ELISA, and analyzed Th1 and Th2 responses in the spleen transcriptionally by real-time PCR and phenotypically by two-color flow cytometry analysis. It showed that deletion of Smad3 suppressed the Th1 but promoted the Th2 responses in the spleen during cardiac allograft rejection (Figure 6A-6C).

\section{Deletion of Smad3 suppresses Th17-mediated acute cardiac allograft rejection, while impairing the Treg response}

Since TGF- $\beta 1$, together with IL-6, plays a critical role in regulating Th17 immune response [8], we thus examined whether Smad3 functions to regulate the Th17mediated allograft rejection in the donor heart. Two-color immunofluorescence and flow cytometry analysis revealed a strong Th17 immune response with many $\mathrm{CD} 4^{+} \mathrm{IL}-17 \mathrm{~A}^{+}$ cells in the donor heart of Smad3 WT mice, which was largely suppressed in mice lacking Smad3, with a 50\%

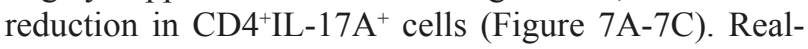
time PCR and western blot analysis further supported this notion that deletion of Smad3 markedly suppressed the expression of TGF- $\beta 1$, IL- 6 , a transcriptional factor ROR $\gamma$ t, and its signature cytokine IL-17A locally in the grafted heart tissues (Figure 8A and 8B).

It has been reported that TGF- $\beta 1$ is a key inducer for the Treg development via a Smad3-dependent mechanism [9]. We thus investigated the Treg response in the grafted heart tissues in Smad3 KO mice. Two color immunofluorescence and flow cytometry analysis showed that deletion of Smad3 impaired the Treg response in the grafted heart tissues as demonstrated by a significant decrease in $\mathrm{CD}^{+} \mathrm{Foxp}^{+}$cells (Figure 7D-7F), which was further confirmed by real-time PCR and western blot analysis with a marked inhibition of the Foxp3 transcriptional factor and IL-10 expression (Figure 8C and 8D).

Interestingly, consistent with the finding in the grafted heart, real-time PCR detected expression of Foxp3 and IL-10 mRNA in the spleen was suppressed in Smad3 $\mathrm{KO}$ recipients, which was associated with inhibition of $\mathrm{CD}^{+}{ }^{+} \mathrm{Foxp}^{+}$Treg population as demonstrated by ELISA and two-color flow cytometry analysis (Figure 6D-6F). In contrast, Th17 response in the spleen was increased in Smad3 KO mice when compared to Smad3 WT mice during cardiac allograft rejection (Figure 6D-6F).

\section{DISCUSSION}

The present study demonstrated that mice lacking Smad3 developed less severe allograft rejection and improved the allograft survival rate in cardiac transplantation. This protective effect on acute cardiac allograft rejection was associated with a marked inhibition of cardiac inflammation and Th1 and Th17 immune response. However, we also found that mice null for Smad3 promoted Th2 immunity while impairing the Treg cell development. Results from this study suggested that Smad3 is an important regulator of $\mathrm{T}$ cell immunity and differentially regulates the $\mathrm{T}$ cell immune response during acute cardiac transplantation rejection.

It is well known that TGF- $\beta$ plays a crucial role in $\mathrm{T}$ cell survival, proliferation and differentiation and is required for induction and maintenance of transplantation tolerance by induction of Treg cells [1, 4, 10-12]. Results from this study demonstrated that Smad3 was a key regulator of TGF- $\beta$ signaling that diversely regulates the $\mathrm{T}$ cell immunity during cardiac allograft rejection. It is now clear that TGF- $\beta / \mathrm{Smad} 3$ signaling is essential for the induction of Foxp3 and the development of Tregs [13], which is critical in the induction and maintenance of 

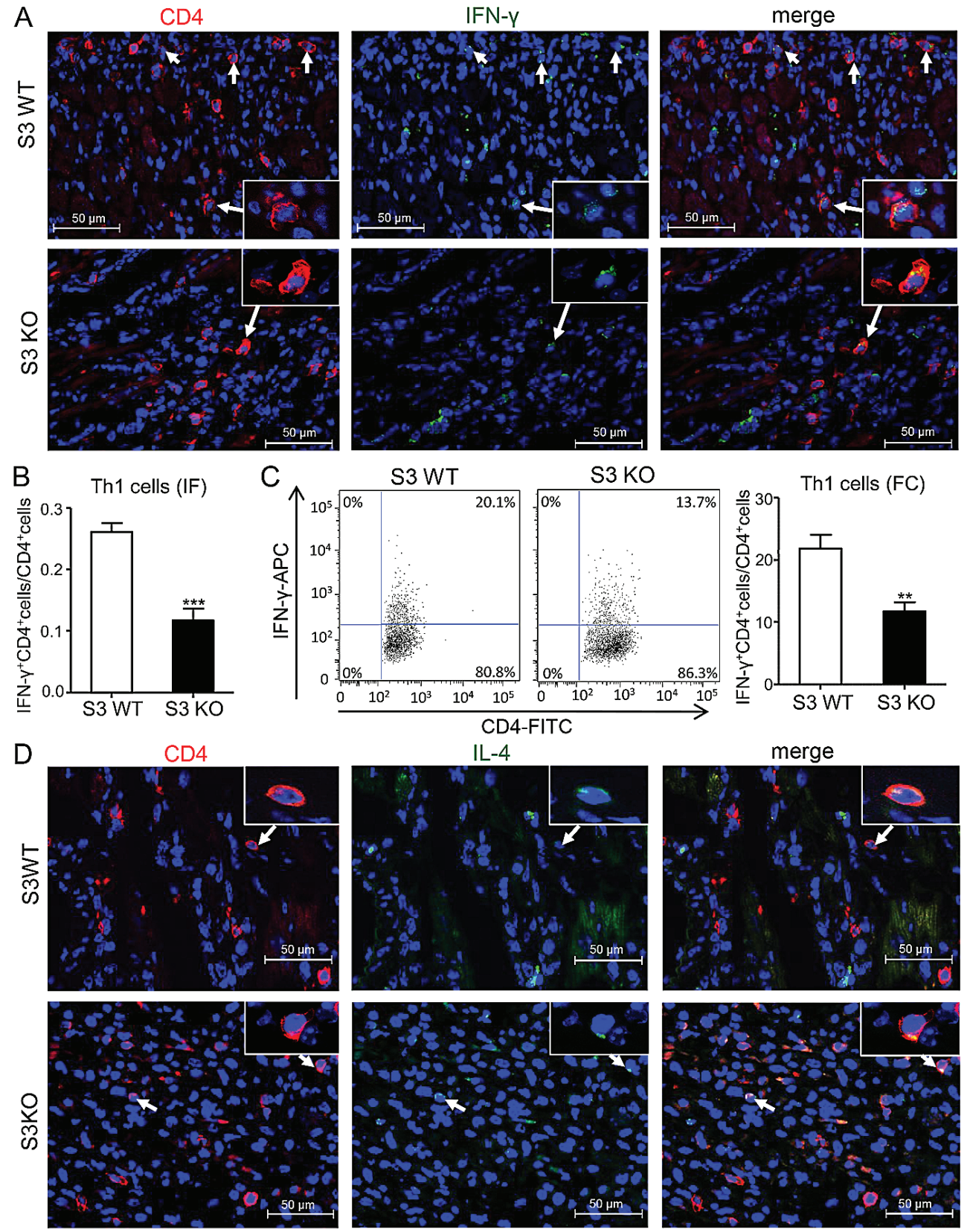

E
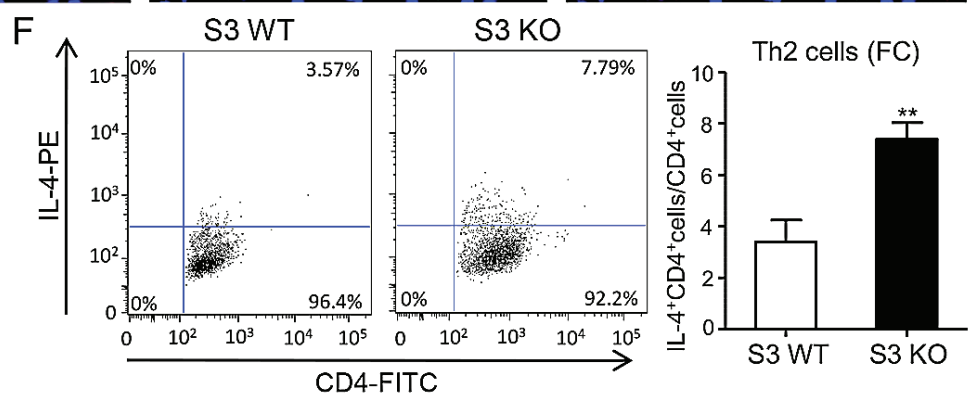

Figure 4: Deletion of Smad3 suppresses Th1 but enhances Th2 cells infiltrating the cardiac allografts. A. Two-color immunofluorescence for detecting Th1 cells $\left(\mathrm{CD} 4+\mathrm{IFN}-\gamma^{+}\right)$infiltrating the allografts on POD 7. B. Quantitative data of Th1 cells on two-color immunofluorescence-staining sections. C. Quantitative analysis of CD4 ${ }^{+} \mathrm{IFN}-\gamma^{+}$cells by two-color flow cytometry in cardiac allografts of Smad3 KO and WT recipients on POD 7. D. Two-color immunofluorescence for detecting Th2 cells $\left(\mathrm{CD} 4^{+} \mathrm{IL}-4^{+}\right)$infiltrating the allografts on POD 7. B. Quantitative data of Th2 cells on two-color immunofluorescence-staining sections. C. Quantitative analysis of $\mathrm{CD} 4^{+} \mathrm{IL}-4^{+}$cells by two-color flow cytometry in cardiac allografts of Smad3 KO and WT recipients on POD 7. Data are expressed as the mean \pm SEM. $* * p<0.01, * * * p<0.001$ versus Smad3 WT mice. 

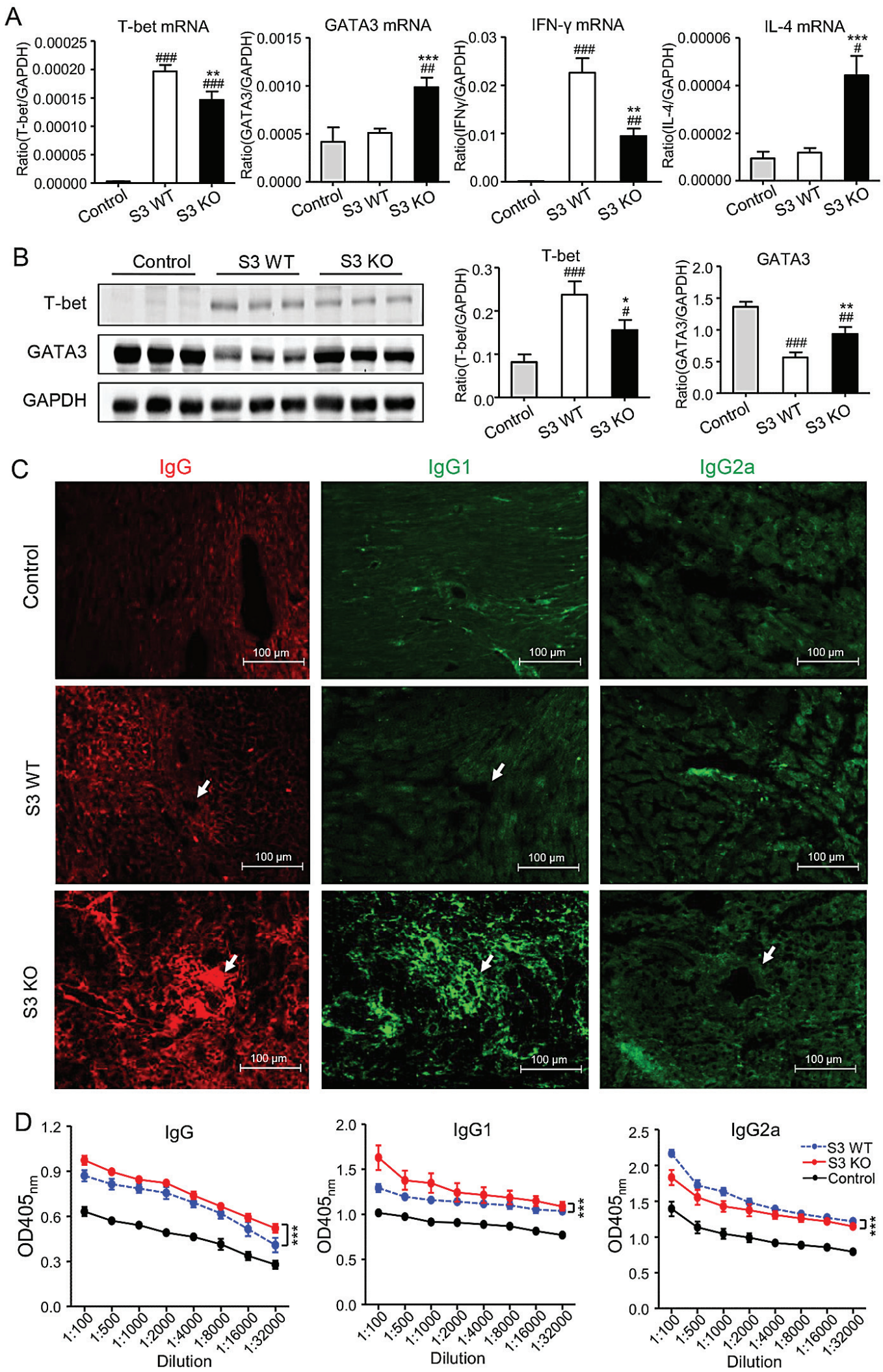

Figure 5: Smad3-deficient mice are more likely to suffer a Th2-type immune response, while suppressing Th1-type immune response in cardiac allografts. A. Real-time PCR for T-bet, GATA3, IFN- $\gamma$ and IL-4 mRNA expression in cardiac allografts on POD 7. B. Western blot analysis shows the expression of T-bet and GATA3 in cardiac allografts in control, Smad $3 \mathrm{KO}$ and WT recipients on POD 7. C. Immunofluorescence shows the total IgG, IgG1 and IgG2a deposition within the cardiac allograft tissues on POD 7. D. Serum levels of IgG, IgG1 and IgG2a in control, Smad3 KO and WT recipients on POD 7 detected by ELISA. Data are expressed as the mean \pm SEM. ${ }^{*} p<0.05,{ }^{* *} p<0.01,{ }^{* * *} p<0.001$ versus Smad3 WT mice; $\# p<0.05, \# \# p<0.01, \# \# p<0.001$ versus control mice. 

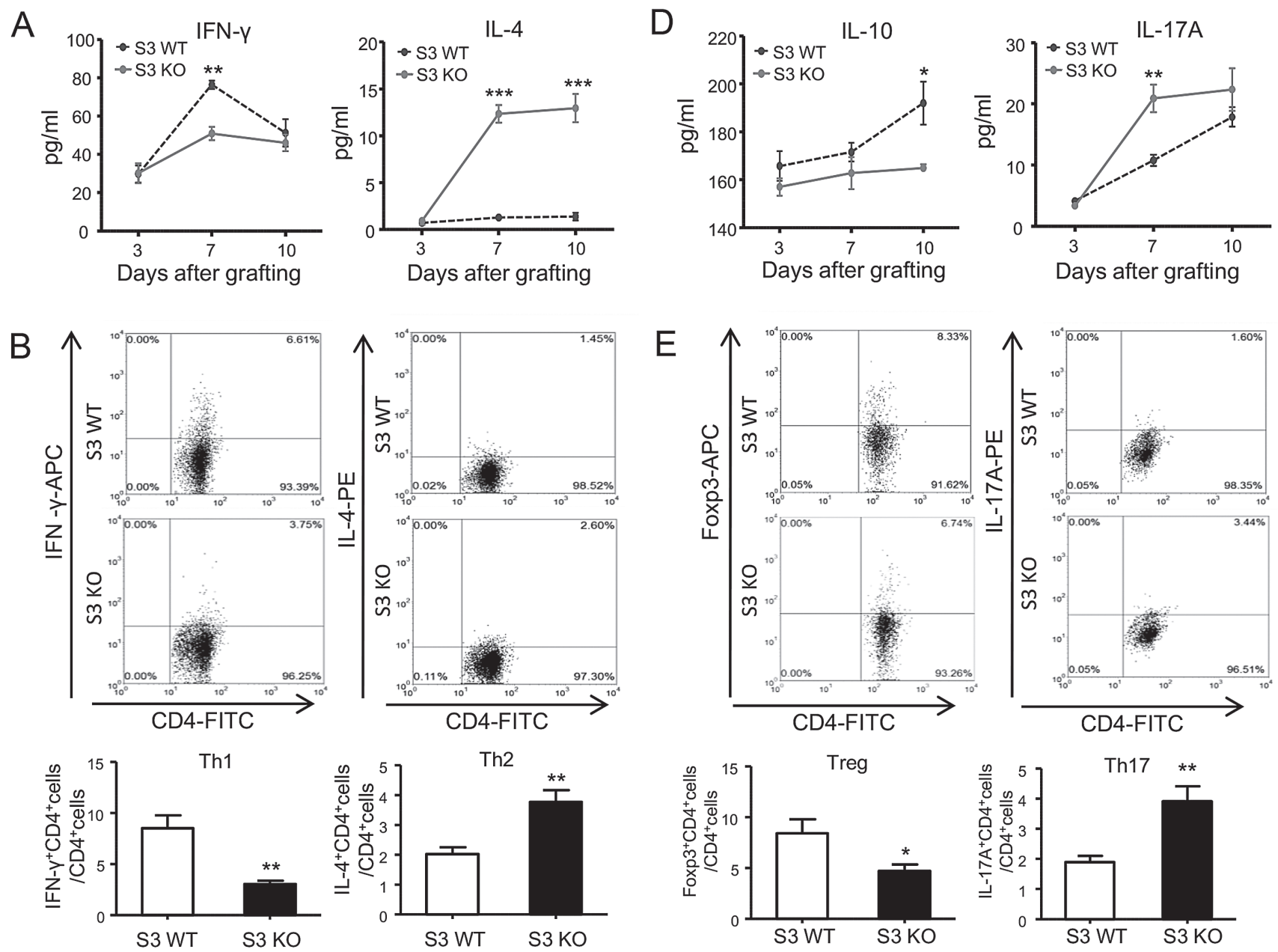

C
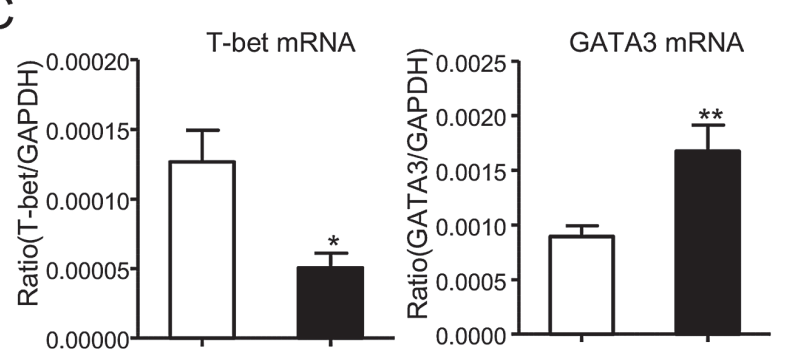

$\mathrm{F}$
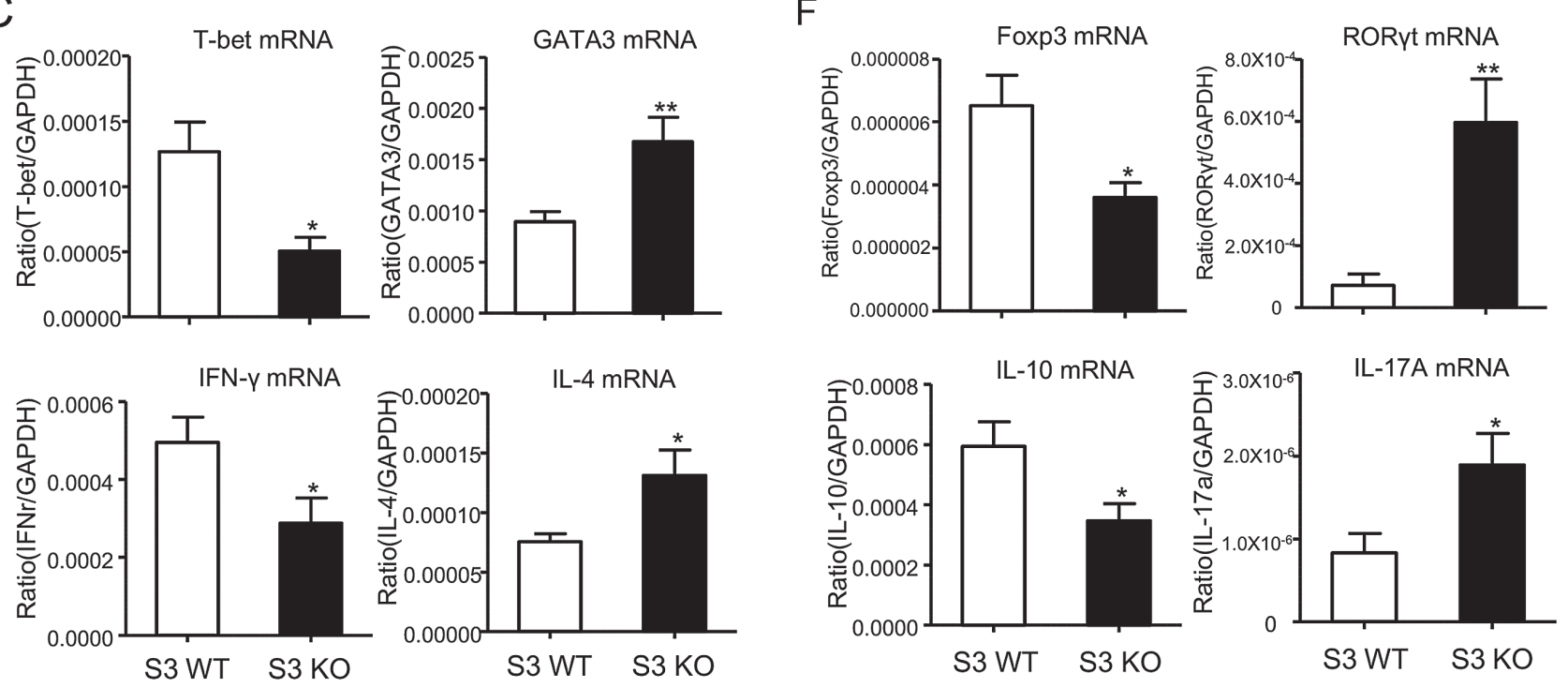

Figure 6: Deletion of Smad3 differentially regulates $T$ cell differentiation during cardiac allograft rejection. A., $D$. Serum levels of IFN- $\gamma$, IL-4, IL-10 and IL-17A in Smad3 KO and WT recipients on POD 7 detected by ELISA. B., E. Quantitative analysis of $\mathrm{CD}^{+} \mathrm{IFN}-\gamma^{+}$cells, $\mathrm{CD} 4^{+} \mathrm{IL}-4^{+}$cells, $\mathrm{CD}^{+} \mathrm{Foxp}^{+}$cells and $\mathrm{CD} 4^{+} \mathrm{IL}-17 \mathrm{~A}^{+}$cells by two-color flow cytometry analysis in the spleen of Smad3 KO and WT recipients on POD 7. C., F. Real-time PCR analysis of T-bet, GATA3, Foxp3, ROR $\gamma$ t, IFN- $\gamma$, IL-4, IL-10 and IL-17A mRNA expression in the spleen of Smad3 KO and WT recipients on POD 7. Data are expressed as the mean \pm SEM. ${ }^{*} p<0.05,{ }^{* *} p<0.01$, $* * * p<0.001$ versus Smad3 WT mice. 

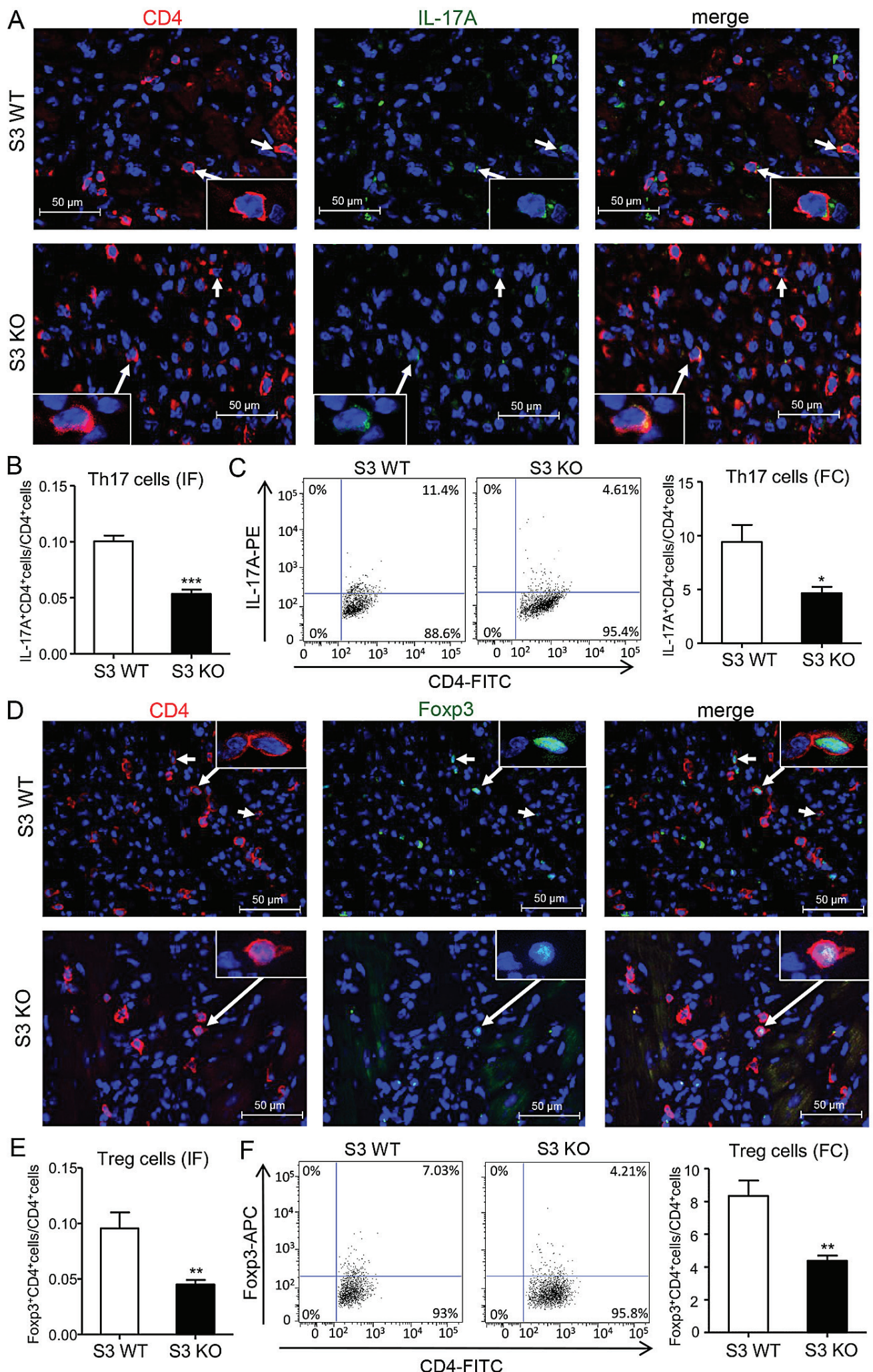

Figure 7: Deletion of Smad3 suppresses Th17 and Treg cells infiltrating the cardiac allografts. A. Two-color immunofluorescence for detecting Th17 cells $\left(\mathrm{CD} 4+\mathrm{IL} 17 \mathrm{~A}^{+}\right)$infiltrating the allografts on POD 7. B. Quantitative data of Th17 cells on two-color immunofluorescence-staining sections. C. Quantitative analysis of $\mathrm{CD} 4^{+} \mathrm{IL} 17 \mathrm{~A}^{+}$cells by two-color flow cytometry in cardiac allografts of Smad $3 \mathrm{KO}$ and WT recipients on POD 7. D. Two-color immunofluorescence for detecting Treg cells $\left(\mathrm{CD} 4^{+} \mathrm{Foxp} 3^{+}\right)$infiltrating the allografts on POD 7. B. Quantitative data of Treg cells on two-color immunofluorescence-staining sections. C. Quantitative analysis of $\mathrm{CD}^{+} \mathrm{Foxp}^{+}$cells by two-color flow cytometry in cardiac allografts of Smad3 KO and WT recipients on POD 7. Data are expressed as the mean \pm SEM. ${ }^{*} p<0.05, * * p<0.01, * * * p<0.001$ versus Smad3 WT mice. 
transplantation tolerance. Smad3 binding to the enhancer of Foxp3 gene is a necessary step in Treg induction [13, 14]. The finding from this study showed that mice lacking Smad3 impaired the Treg cell development systemically, resulting in a loss of Treg response locally in grafted heart. This suggests a crucial role for Smad 3 in TGF- $\beta$-induced immune tolerance during transplant rejection. However, consistent with a previous finding in skin transplantation rejection [15], deletion of $\mathrm{Smad} 3$ resulted in the improvement of the cardiac allograft survival despite of the loss of Treg cells. Although outcome from this study did not fully support the essential role for TGF- $\beta / \mathrm{Smad} 3$ signaling in the induction of transplantation tolerance, it does suggest the complexity of Smad3 in regulating allograft rejection, which was further discussed below.

In the present study, we found that deletion of Smad3 resulted in the suppression of the Th17-mediated allograft rejection as detected by a marked inhibition of the transcriptional factor ROR $\gamma t$ and its signature cytokine IL-17A in the donor heart. In contrast, deletion of Smad3 promoted Th17 development with higher levels of Th17 response in the spleen of Smad3 KO recipients. This discrepant finding suggests that differential mechanisms may operate in the local versus systemic Th17 responses. It is well established that Th17-driven immune response plays a critical role in acute allograft rejection [16]. In the presence of IL- 6 , TGF- $\beta 1$ induces the generation of IL-17-producing $\mathrm{T}$ cells $[17,18]$. In the present study, we found that Smad3-deficency inhibited both TGF- $\beta 1$ and IL-6 expression locally in the transplanted heart, thereby suppressing RORt-driven IL-17A expression and $\mathrm{CD}^{+} \mathrm{IL}_{17 \mathrm{~A}^{+}}$cell-mediated acute cardiac allograft rejection. This finding was consistent with a previous study that inhibition of Smad3 attenuates Th17-mediated
A
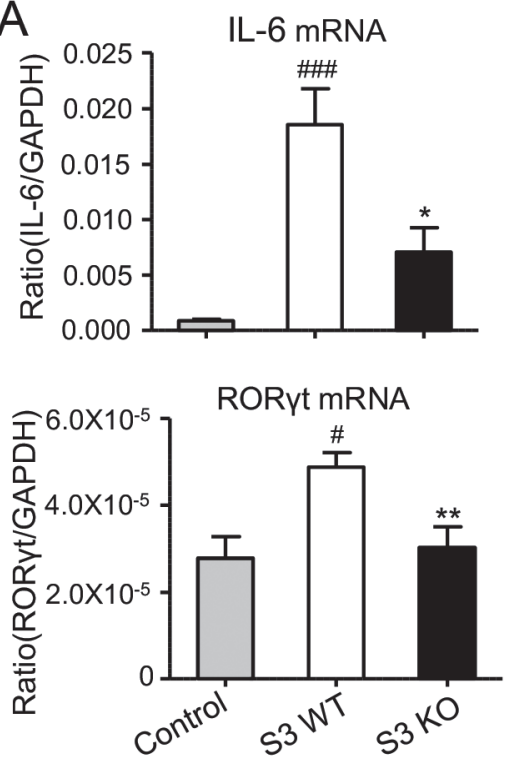

C

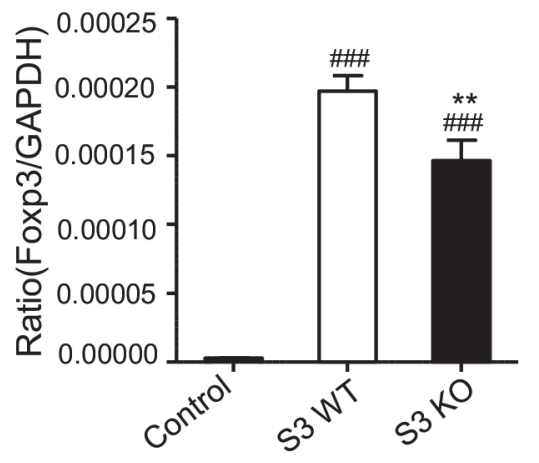

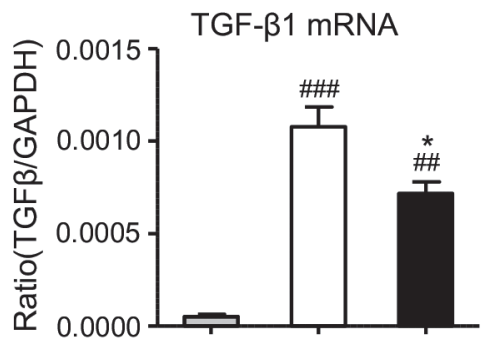

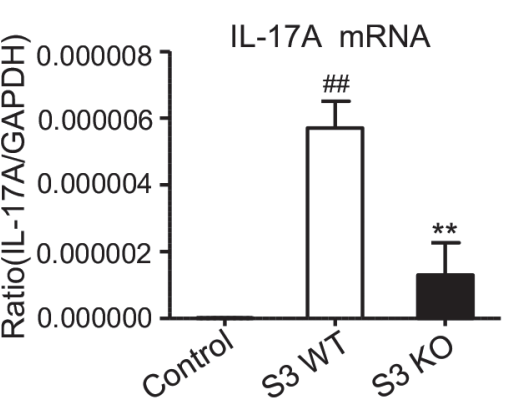

IL-10 mRNA

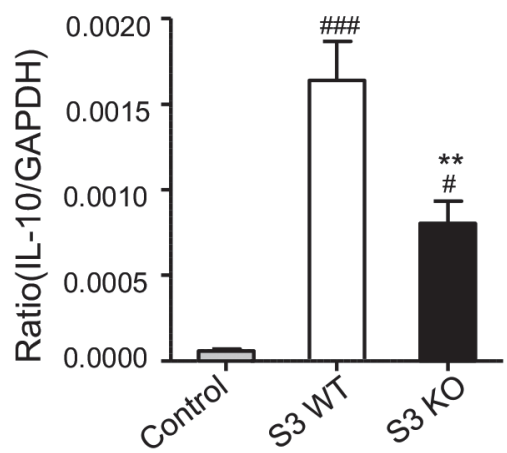

B
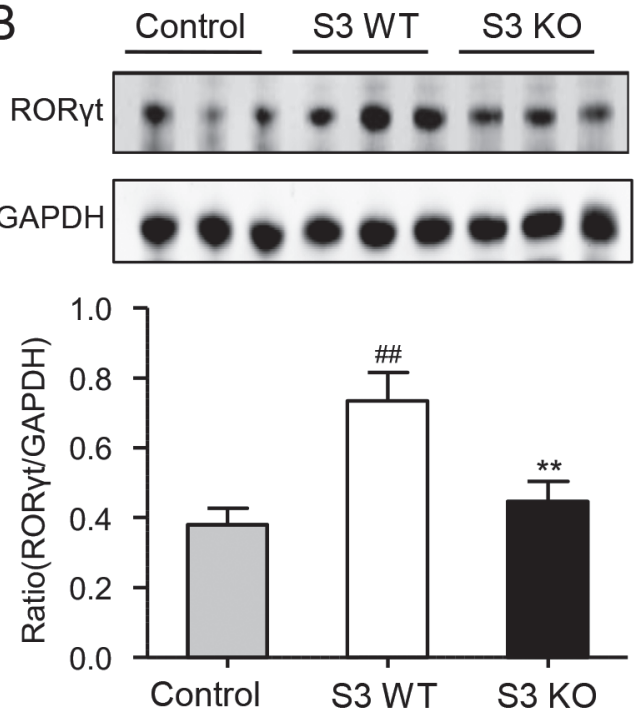

D
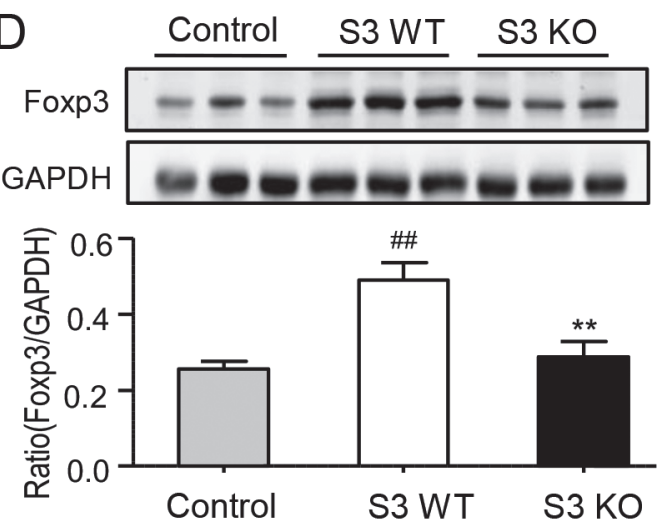

Figure 8: Deletion of Smad3 from the recipients suppresses Th17 and Treg immune response in cardiac allografts. A. Real-time PCR for IL-6, TGF- $\beta 1$, ROR $\gamma$ t, and IL-17A mRNA expression in cardiac allografts on POD 7. B. Western blot analysis shows the expression of ROR $\gamma \mathrm{t}$ in cardiac allografts in control, Smad3 KO and WT recipients on POD 7. C. Real-time PCR for Foxp3 and IL-10 mRNA expression in cardiac allografts on POD 7. D. Western blot analysis shows the expression of ROR $\gamma t$ in cardiac allografts in control, Smad3 KO and WT recipients on POD 7. Data are expressed as the mean \pm SEM. ${ }^{*} p<0.05, * * p<0.01$ versus Smad3 WT mice; \#p $<0.05$, $\# \# p<0.01, \# \# p<0.001$ versus control mice. 
skin lesions in a mouse model of psoriasis [19]. In contrast, higher level of Th17 response was found in the spleen of Smad3 KO recipients. This may be associated with the loss of Foxp3 because Foxp3 can inhibit Th17 cell differentiation by antagonizing $\operatorname{ROR} \gamma \mathrm{t}$ [20]. Thus, it is highly possible that loss of Smad3 may suppress Th17mediated acute allograft rejection locally by blocking its upstream signaling including inhibition of TGF- $\beta 1$ and IL-6. However, deletion of Smad3 may promote the Th17 development systemically in the lymphoid tissues due to the loss of Foxp3-dependent inhibition of ROR $\gamma \mathrm{t}$ expression.

An interesting finding in this study was that loss of Smad3 from the recipients resulted in a shift of immune response from the Th1 to the Th2 in cardiac allografts, which is consistent with the alloskin rejection [15]. This shift from the Th1 to Th2 immune response locally in the grafted heart was associated with the impaired Th1 but enhanced Th2 differentiation systemically in the spleen tissue. Generally, Th1 cells are responsible for the induction and maintenance of the cellular immunity, while Th2 cells drive the humoral response [21]. In transplant rejection, Th1 cells promote allograft rejection characterized by increasing the Th1 reactivity with high levels of IL-2 and IFN- $\gamma$ within the grafted tissues [22]. Th2 cytokines, particularly IL-4 and IL-10, are believed to inhibit the Th1 response in allograft rejection [23]. In the present study, the shift of allograft rejection from Th1 to Th2 response may be another mechanism whereby Smad3-deficiency improved allograft survival, although mechanisms remain largely unclear. It has been shown that Smad3 is essential for TGF- $\beta 1$ signaling to inhibit the differentiation of $\mathrm{Th} 1$ and $\mathrm{Th} 2$ subsets [24, 25]. However, results from our study did not fully support this notion, suggesting Smad3-dependent and independent mechanisms in the regulation of the Th1/Th2 immunity. It is well established that differentiation of $\mathrm{CD}^{+} \mathrm{T}$ cells to the Th1 phenotype is regulated by T-bet, a Th1-specific transcription factor that initiates Th1 development while inhibiting Th2 cell differentiation $[26,27]$. In contrast, GATA-3, a member of the GATA family of zinc finger proteins, plays a pivotal role in the development of the Th2 phenotype while inhibiting Th1 cells [28]. The interrelation between the T-bet and the GATA-3 determines the balance of Th1 and Th2 development [29]. T-bet has a binding ability to GATA-3, CBP/P300, and $\mathrm{Sp} 1$ to form a transcription factor complex [29]. The principal function of T-bet in developing Th1 cells is to negatively regulate GATA-3 [29, 30]. Thus, T-bet deficient $\mathrm{CD}^{+} \mathrm{T}$ cells are skewed toward Th2 differentiation by high endogenous GATA-3 level [29]. Whereas, GATA-3 shuts down Th1 and induces Th2 development through the repression of Stat 4 and augments its own expression by a positive feedback autoregulation mechanism [28, 30]. It is found that Smad3 is physically associated with GATA-3 and treatment of T cells with TGF- $\beta$ promotes the formation of Smad3/GATA-3 nuclear complex and regulates IL-5 promoter activity and IL-10 production in a Smad3- and GATA-3-dependent manner [31]. This finding may explain the signaling mechanism by which TGF- $\beta$ inhibits IL-4-induced GATA-3 expression on $\mathrm{CD}^{+} \mathrm{T}$ cells and suppresses IL-4-mediated Th2 differentiation [32]. Thus, deletion of Smad3 resulted in a loss of the inhibitory effect of TGF- $\beta$ on GATA-3. Once GATA-3 is upregulated, expression of T-bet is suppressed, thereby promoting Th2 but suppressing Th1 mediated cardiac allograft rejection. Results obtained from this study also support the notion that the T-bet/GATA-3 ratio is important in determining the balance of Th1/Th2 immune response [33]. However, in this study, deletion of Smad3 inhibited IL-10 expression, which was inconsistent with previous study [15]. Since IL10 is an important pleiotropic immunoregulatory cytokine secreted by different cell types, including macrophages, Th2 cells, and Treg cells et al [34], It is highly possible that inhibition of IL-10 expression in Smad3 KO mice during cardiac allograft rejection may be associated with inhibition of macrophage infiltration and importantly the loss of Treg response.

Inhibition of innate immunity may also account for the protective effect on cardiac allograft rejection in Smad3 KO mice. Recent studies showed that allograft rejection mounted by adaptive immune cells is shaped by the innate immunity [35]. Among them, macrophages are a key mediator [36]. Consistent with this finding, we also found that macrophage infiltration to the cardiac allograft in Smad3 KO recipients was less prominent. This may be associated with the impairment of Smad3 KO monocytes to the chemotaxis to TGF- $\beta 1$ since Smad3 is a critical for TGF- $\beta$-induced MCP-1 expression $[37,38]$. In addition, mice lacking Smad3 exhibited a marked inhibition of neutrophil infiltration and expression of proinflammatory cytokines IL-1 $\beta$, TNF- $\alpha$, and MCP- 1 . All these findings are consistent with many previous studies in which deletion of Smad3 protects against inflammatory response during ischemic and hypertensive cardiac remodeling [38, 39].

In summary, deletion of Smad3 from the recipients results in the improvement of cardiac allograft survival, which may be associated with inhibition of the Th1 and Th17 immune response. However, Smad3-deficiency also results in a loss of Treg cells and promotes Th2-dependent humoral cardiac allograft rejection. Results from this study suggest that $\mathrm{Smad} 3$ is a critical immune regulator in maintaining the $\mathrm{T}$ cell immunity during transplantation rejection. 


\section{MATERIALS AND METHODS}

\section{A mouse model of acute cardiac allograft rejection}

Smad3 KO and wild-type (WT) mice (H-2 ${ }^{\text {b }}$, both sexes, age 8 weeks, $n=6$ /group), congenic to the $\mathrm{C} 57 \mathrm{BL} / 6$ strain [7], and BALB/c mice $\left(\mathrm{H}-2^{\mathrm{d}}\right.$, both sexes, age 8 weeks), were used in this study. A mouse model of cardiac allograft rejection was induced by transplanting the donor hearts from BALB/c mice into the abdomen of Smad3 $\mathrm{KO}$ and WT mice [40]. Cardiac transplantation of donor hearts from $\mathrm{BALB} / \mathrm{c}$ mice into the abdomen of $\mathrm{BALB} / \mathrm{c}$ mice was used as control. All transplant experiments were performed using sex-matched animals. Manipulations were performed according to the Department of Health (Hong Kong) guidelines in Care and Use of Animals and with approval of the Animal Experimentation Ethics Committee at the Chinese University of Hong Kong. Graft viabilities were assessed by daily abdominal palpation. Undetectable heart impulses for two consecutive days were considered as rejection.

\section{ELISA}

To test humoral immune response, serum immunoglobulin levels were measured by enzyme-linked immunosorbent assay (ELISA). Briefly, 96-well plates were coated with rabbit anti-mouse immunoglobulin $\mathrm{G}$ (IgG) (Sigma, St Louis, MO, USA) for overnight at $4^{\circ} \mathrm{C}$ and blocked with $2 \%$ BSA in PBS for 2 hours at room temperature. Then gradient dilutions of mouse serum in duplicate were added and incubated overnight. The bound anti-mouse IgG were detected with horseradish peroxadise (HRP) conjugated rabbit anti-mouse IgG (Dako, Glostrup, Denmark), IgG1 and IgG2a (Sigma) antibodies and the reaction optical density (OD) was determined at $405 \mathrm{~nm}$. Serum levels of IFN- $\gamma$, IL-4, IL-10 and IL-17A were tested using ELISA kit (Biolegend, CA, USA).

\section{Flow cytometry analysis}

Graft heart and spleen tissues were digested by blenzyme 4 (Roche Inc, Indianapolis, IN, USA) into cell suspension. The white blood cells were then enriched by centrifugation through discontinuous Percoll (Pharmacia Fine Chemicals, Uppsala, Sweden) density gradients $(40 \%, 60 \%$ and $80 \%)$. After being stimulated with Cell Stimulation Cocktail (plus protein transport inhibitors, eBioscience, San Diego, CA, USA) for 12 hours in $\mathrm{CO}_{2}$ incubator, the gathered cells were fixed for 30 minutes in IC Fixation Buffer (eBioscience) and permeablized by $1 \mathrm{x}$ Permeabilization Buffer (eBioscience) for 30 minutes. Then cells were stained with fluorescein isothiocyanate
(FITC) -conjugated anti-mouse CD4, allophycocyanin (APC) -conjugated IFN- $\gamma$, phycoerythrin (PE) -conjugated IL-4, Foxp3-APC or IL-17A-PE (eBioscience) for overnight at $4^{\circ} \mathrm{C}$. After being extensively washed, single cells were analyzed by FACSCaibur flowcytometer (BD Biosciences, San Jose, CA).

\section{Histology and immunohistochemistry}

Grafts were fixed in formalin and embedded in paraffin for $\mathrm{H} \& \mathrm{E}$ stain and immunohistochemistry (IHC) as described previously [41]. Periodate-lysineparaformaldehyde (PLP) fixed, OCT-embedded $5 \mu \mathrm{m}$ sections were stained with antibodies against mouse CD4 (Leinco, St. Louis, MO), IFN- $\gamma$ (eBioscience), IL-4 (eBioscience), Foxp3 (eBioscience), IL-17A (Abcam, Cambridge, UK), F4/80 (Serotec, Oxford, UK), CD3 (Abcam), CD11c (eBioscience), Neutrophil Marker Antibody (NIMP-R14), IL-1 $\beta$, tumor necrosis factor- $\alpha$ (TNF- $\alpha$ ), and monocyte chemoattractant protein-1 (MCP1) (Santa Cruz Biotechnology, Santa Cruz, CA, USA). In addition, immunoglobulin deposition was detected by immunofluorescence (IF) in the OCT-embedded snapfrozen sections $(4 \mu \mathrm{m})$ with antibodies including the PEconjugated anti-mouse IgG (Rockland Immunochemicals, Gilbertsville, PA, USA), IgG1 (Santa Cruz), and IgG2a (South Biotech, Birmingham, AL). Positive cells and cytokines infiltration were quantified in at least 10 consecutive high power fields $(\times 200, \times 400)$ using Imageproplus 7.0 software and expressed as percent positive area or number of positive cells $/ \mathrm{cm}^{2}$ as previously described [42].

\section{Real-time PCR}

Total RNA from the heart and spleen were isolated using the RNeasy kit (Qiagen Inc, Valencia, CA, USA). mRNA expression of IL- $1 \beta$, MCP- 1 , TNF- $\alpha$, T-bet, IFN- $\gamma$, GATA3, IL-4, ROR $\gamma$ t, IL-17A, TGF- $\beta 1$, IL-6, Foxp3, IL-10 and glyceraldehyde-3-phosphate dehydrogenase (GAPDH) was detected by real-time polymerase chain reaction (PCR) with the Opticon 2 Real-Time PCR detector (Bio-Rad) using the primers as previously described [19, 42-45] and below: GATA3: forward 5'-TCTGGAGGAGGAACGCTAAT-3', reverse 5'-TTCGGGTCTGGATGCCTTCTTT-3'; IL4: forward 5'-TTCTCGAATGTACCAGGAGCCA-3', reverse 5'-TCGTTGCTGTGAGGACGTTT-3'; IL10: 5'-AAGGGTTACTTGGGTTGCCA-3', reverse 5'-TGCTCCACTGCCTTGCTCTTAT-3'; ROR $\gamma \mathrm{t}$ : forward 5'-TGTCCTGGGCTACCCTACTG-3', reverse 5'-GTGCAGGAGTAGGCCACATT-3'. The ratio of interested mRNA against GAPDH was calculated and expressed as the mean \pm standard error of the mean (SEM). 


\section{Western blot analysis}

Protein from graft tissues was extracted with RIPA lysis buffer for western blot analysis as described previously [38]. Briefly, after blocking, membranes were incubated overnight at $4^{\circ} \mathrm{C}$ with primary antibodies against T-bet (Santa Cruz), GATA3 (Abcam), Foxp3, ROR $\gamma \mathrm{t}$ (Abcam), or GAPDH. After washing, membranes were incubated with LI-COR IRDye 800-labeled secondary antibodies (Rockland). The signal was detected with Odyssey Infrared Imaging System (Li-COR Biosciences, Lincoln, NE) and quantified against the internal loading control GAPDH with ImageJ version 1.48 (NIH, Bethesda, $\mathrm{MD})$. The ratio of interested protein against GAPDH was calculated and expressed as the mean \pm SEM.

\section{Statistical analyses}

Data obtained from this study are expressed as the mean \pm SEM. Statistical analyses were performed using $t$ test and one-way analysis of variance (ANOVA), followed by Newman-Keuls' multiple comparison test using GraphPad Prism 5.0. The graft survival curves were calculated by the Kaplan-Meier method and the log-rank test was used for graft survival comparison. A $p$ value $<$ 0.05 was considered statistically significant.

\section{ACKNOWLEDGMENTS}

We would like to thank Dr Chuxia Deng from NIH, USA for kindly providing Smad3 KO mice for this study.

\section{FUNDING}

This study was supported by the grants National Nature Science Foundation of P.R.China (2011BAI10B07, 2012CB517603, 2012AA02A512, 2014KYA057), the National Fund Committee of China (81470938), the Research Grant Council of Hong Kong (GRF 468711, CUHK3/CRF/12R), and the Focused Investment Scheme A from Chinese University of Hong Kong

\section{CONFLICTS OF INTEREST}

The authors declare that there are no conflicts of interest.

\section{REFERENCES}

1. Wood KJ, Bushell A and Hester J. Regulatory immune cells in transplantation. Nature Reviews Immunology. 2012; $12: 417-430$

2. Krieger NR, Yin D and Fathman CG. CD4+ but not CD8+ cells are essential for allorejection. The Journal of experimental medicine. 1996; 184:2013-2018.

3. Plenter RJ, Grazia TJ, Doan AN, Gill RG and Pietra BA. CD4 $\mathrm{T}$ cells mediate cardiac xenograft rejection via host MHC Class II. The Journal of Heart and Lung Transplantation. 2012; 31:1018-1024.

4. Li MO and Flavell RA. TGF- $\beta$ : a master of all T cell trades. Cell. 2008; 134:392-404.

5. Li MO, Wan YY, Sanjabi S, Robertson A-KL and Flavell RA. Transforming growth factor- $\beta$ regulation of immune responses. Annu Rev Immunol. 2006; 24:99-146.

6. Lan HY. Diverse roles of TGF- $\beta /$ Smads in renal fibrosis and inflammation. International journal of biological sciences. 2011; 7:1056.

7. Yang X, Letterio JJ, Lechleider RJ, Chen L, Hayman R, Gu $\mathrm{H}$, Roberts AB and Deng C. Targeted disruption of SMAD3 results in impaired mucosal immunity and diminished $\mathrm{T}$ cell responsiveness to TGF- $\beta$. The EMBO journal. 1999; 18:1280-1291.

8. Bettelli E, Carrier Y, Gao W, Korn T, Strom TB, Oukka M, Weiner HL and Kuchroo VK. Reciprocal developmental pathways for the generation of pathogenic effector TH17 and regulatory T cells. Nature. 2006; 441:235-238.

9. Xu L, Kitani A, Stuelten C, McGrady G, Fuss I and Strober W. Positive and negative transcriptional regulation of the Foxp3 gene is mediated by access and binding of the Smad3 protein to enhancer I. Immunity. 2010; 33:313-325.

10. Lee KM, Stott RT, Zhao G, SooHoo J, Xiong W, Lian MM, Fitzgerald L, Shi S, Akrawi E and Lei J. TGF- $\beta$-producing regulatory $\mathrm{B}$ cells induce regulatory $\mathrm{T}$ cells and promote transplantation tolerance. European journal of immunology. 2014; 44:1728-1736.

11. Regateiro FS, Howie D, Cobbold SP and Waldmann H. TGF- $\beta$ in transplantation tolerance. Current opinion in immunology. 2011; 23:660-669.

12. Watson D, Zhang GY, Hu M, Wang Y-M, Fletcher J, Sartor $\mathrm{M}$ and Alexander SI. Transforming growth factor beta (TGF $\beta$ ) plays a crucial role in prolonging allograft survival in an allodepletion ("pruning") skin transplant model. Transplant immunology. 2014; 30:168-177.

13. Schlenner SM, Weigmann B, Ruan Q, Chen Y and von Boehmer H. Smad3 binding to the foxp3 enhancer is dispensable for the development of regulatory $\mathrm{T}$ cells with the exception of the gut. The Journal of experimental medicine. 2012; 209:1529-1535.

14. Tone Y, Furuuchi K, Kojima Y, Tykocinski ML, Greene MI and Tone M. Smad3 and NFAT cooperate to induce Foxp3 expression through its enhancer. Nature immunology. 2008; 9:194-202.

15. Wu T, Sun C, Chen Z, Zhen Y, Peng J, Qi Z, Yang X and Zhao Y. Smad3-Deficient CD11b+ Gr1+ Myeloid-Derived Suppressor Cells Prevent Allograft Rejection via the Nitric Oxide Pathway. The Journal of Immunology. 2012; 189:4989-5000.

16. Sullivan JA, Adams AB and Burlingham WJ. The emerging 
role of Th17 cells in organ transplantation. Transplantation. 2014; 97:483-489.

17. Mangan PR, Harrington LE, O'Quinn DB, Helms WS, Bullard DC, Elson CO, Hatton RD, Wahl SM, Schoeb TR and Weaver CT. Transforming growth factor- $\beta$ induces development of the TH17 lineage. Nature. 2006; 441:231234.

18. Veldhoen M, Hocking RJ, Atkins CJ, Locksley RM and Stockinger B. TGF $\beta$ in the context of an inflammatory cytokine milieu supports de novo differentiation of IL-17producing T cells. Immunity. 2006; 24:179-189.

19. Zhang Y, Meng XM, Huang XR, Wang XJ, Yang L and Lan HY. Transforming growth factor- $\beta 1$ mediates psoriasislike lesions via a Smad3-dependent mechanism in mice. Clinical and Experimental Pharmacology and Physiology. 2014; 41:921-932.

20. Zhon L, Lopes JE and Chong MM. TGF-beta-induced Foxp3 inhibits Thl7 cell differentiation by antagonizing ROR gammat func-tionE J. Nature. 2008; 453:236-240.

21. Kidd P. Th1/Th2 balance: the hypothesis, its limitations, and implications for health and disease. Alternative Medicine Review. 2003; 8:223-246.

22. Zelenika D, Adams E, Humm S, Lin CY, Waldmann H and Cobbold SP. The role of CD4+ T cell subsets in determining transplantation rejection or tolerance. Immunological reviews. 2001; 182:164-179.

23. Waaga AM, Gasser M, Kist-van Holthe JE, Najafian N, Müller A, Vella JP, Womer KL, Chandraker A, Khoury SJ and Sayegh MH. Regulatory functions of self-restricted MHC class II allopeptide-specific Th2 clones in vivo. Journal of Clinical Investigation. 2001; 107:909.

24. Giroux M, Delisle J-S, Gauthier S-D, Heinonen KM, Hinsinger J, Houde B, Gaboury L, Brochu S, Wu J and Hébert M-J. SMAD3 prevents graft-versus-host disease by restraining Th1 differentiation and granulocyte-mediated tissue damage. Blood. 2011; 117:1734-1744.

25. McKarns SC, Schwartz RH and Kaminski NE. Smad3 is essential for TGF- $\beta 1$ to suppress IL-2 production and TCRinduced proliferation, but not IL-2-induced proliferation. The Journal of Immunology. 2004; 172:4275-4284.

26. Szabo SJ, Kim ST, Costa GL, Zhang X, Fathman CG and Glimcher LH. A novel transcription factor, T-bet, directs Th1 lineage commitment. Cell. 2000; 100:655-669.

27. Zhou M and Ouyang W. The function role of GATA-3 in Th1 and Th2 differentiation. Immunologic research. 2003; 28:25-37.

28. Chen G-Y, Osada H, Santamaria-Babi LF and Kannagi R. Interaction of GATA-3/T-bet transcription factors regulates expression of sialyl Lewis X homing receptors on Th1/Th2 lymphocytes. Proceedings of the National Academy of Sciences. 2006; 103:16894-16899.

29. Usui T, Preiss JC, Kanno Y, Yao ZJ, Bream JH, O’Shea JJ and Strober W. T-bet regulates Th1 responses through essential effects on GATA-3 function rather than on
IFNG gene acetylation and transcription. The Journal of experimental medicine. 2006; 203:755-766.

30. Usui T, Nishikomori R, Kitani A and Strober W. GATA3 suppresses Th1 development by downregulation of Stat 4 and not through effects on IL-12R $\beta 2$ chain or T-bet. Immunity. 2003; 18:415-428.

31. Blokzijl A, ten Dijke P and Ibáñez CF. Physical and functional interaction between GATA-3 and Smad3 allows TGF- $\beta$ regulation of GATA target genes. Current biology. 2002; 12:35-45.

32. Gorelik L, Fields PE and Flavell RA. Cutting edge: TGF- $\beta$ inhibits Th type 2 development through inhibition of GATA-3 expression. The Journal of Immunology. 2000; 165:4773-4777.

33. Chakir H, Wang H, Lefebvre DE, Webb J and Scott FW. T-bet/GATA-3 ratio as a measure of the Th1/Th2 cytokine profile in mixed cell populations: predominant role of GATA-3. Journal of immunological methods. 2003; 278:157-169.

34. O'Garra A, Vieira PL, Vieira P and Goldfeld AE. IL-10producing and naturally occurring CD4+ Tregs: limiting collateral damage. Journal of Clinical Investigation. 2004; 114:1372.

35. Béland S, Désy O, Vallin P, Basoni C and De Serres SA. Innate immunity in solid organ transplantation: an update and therapeutic opportunities. Expert review of clinical immunology. 2015; 11:377-389.

36. Mannon RB. Macrophages: Contributors to Allograft Dysfunction, Repair or Innocent Bystanders? Current opinion in organ transplantation. 2012; 17:20.

37. Ashcroft GS, Yang X, Glick AB, Weinstein M, Letterio JJ, Mizel DE, Anzano M, Greenwell-Wild T, Wahl SM and Deng C. Mice lacking Smad3 show accelerated wound healing and an impaired local inflammatory response. Nature cell biology. 1999; 1:260-266.

38. Huang XR, Chung ACK, Yang F, Yue W, Deng C, Lau CP, Tse HF and Lan HY. Smad3 mediates cardiac inflammation and fibrosis in angiotensin II-induced hypertensive cardiac remodeling. Hypertension. 2010; 55:1165-1171.

39. Bujak M, Ren G, Kweon HJ, Dobaczewski M, Reddy A, Taffet G, Wang X-F and Frangogiannis NG. Essential role of Smad3 in infarct healing and in the pathogenesis of cardiac remodeling. Circulation. 2007; 116:2127-2138.

40. Hasegawa T, Visovatti SH, Hyman MC, Hayasaki T and Pinsky DJ. Heterotopic vascularized murine cardiac transplantation to study graft arteriopathy. Nature protocols. 2007; 2:471-480.

41. Lan HY, Mu W, Nikolic-Paterson DJ and Atkins RC. A novel, simple, reliable, and sensitive method for multiple immunoenzyme staining: use of microwave oven heating to block antibody crossreactivity and retrieve antigens. Journal of Histochemistry \& Cytochemistry. 1995; 43:97-102.

42. Huang XR, Chung ACK, Zhou L, Wang XJ and Lan HY. Latent TGF- $\beta 1$ protects against crescentic 
glomerulonephritis. Journal of the American Society of Nephrology. 2008; 19:233-242.

43. Tang Y-J, Xiao J, Huang XR, Zhang Y, Yang C, Meng $\mathrm{X}-\mathrm{M}$, Feng Y-L, Wang X-J, Hui DSC and Yu C-M. Latent TGF- $\beta 1$ Protects Against Bleomycin-Induced Lung Injury in Mice. American Journal of Respiratory Cell and Molecular Biology. 2014; (ja).

44. Wong BLW, Zhu S-L, Huang XR, Ma J, Xia HHX, Bucala R, Wong BCY and Lan HY. Essential Role for Macrophage Migration Inhibitory Factor in Gastritis Induced by Helicobacter pylori. The American journal of pathology. 2009; 174:1319-1328.

45. Yang F, Chung ACK, Huang XR and Lan HY. Angiotensin II Induces Connective Tissue Growth Factor and Collagen I Expression via Transforming Growth Factor- $\beta$-Dependent and-Independent Smad Pathways The Role of Smad3. Hypertension. 2009; 54:877-884. 